\title{
Characterization of Chitosan Membranes Crosslinked by Sulfuric Acid
}

\author{
Thiago B. Fideles ${ }^{1}$, José Luis Santos², Helena Tomás², Glória T. F. S. Furtado', Daniel B. Lima1, \\ Silvia M. P. Borges' ${ }^{1}$, Marcus V. L. Fook ${ }^{1}$ \\ ${ }^{1}$ Laboratory of Biomaterials Evaluation and Development-CERTBIO, Materials Engineering Department, Campina Grande \\ Federal University, Campina Grande, Brazil \\ ${ }^{2}$ Centro de Química da Madeira, MMRG, Universidade da Madeira, Funchal, Portugal \\ Email: *tfideles@gmail.com
}

How to cite this paper: Fideles, T. B., Santos, J.L., Tomás, H., Furtado, G.T.F.S., Lima, D.B., Borges, S.M.P. and Fook, M.V.L. (2018) Characterization of Chitosan Membranes Crosslinked by Sulfuric Acid. Open Access Library Journal, 5: e4336.

https://doi.org/10.4236/oalib.1104336

Received: January 13, 2018

Accepted: January 27, 2018

Published: January 30, 2018

Copyright ( 2018 by authors and Open Access Library Inc.

This work is licensed under the Creative Commons Attribution International License (CC BY 4.0).

http://creativecommons.org/licenses/by/4.0/

(c) (i) Open Access

\begin{abstract}
Development of novel biomaterials and its practical application have been the subject of much research in the field of scaffolds for tissue engineering, providing the success of producing scaffolds biomaterials that facilitate tissue growth and provide structure support for cells. Due to its biocompatibility and biodegradability, chitosan has been the focus of several researches in recent years to be applied in the biomedical field and chemical modifications of chitosan through crosslinks can produce materials with a wide variety of properties. The objective of this study was to obtain and characterize, chemically and biologically, ionically crosslinked chitosan membranes. Chitosan membranes were prepared by solvent evaporation and the crosslinks were introduced by reaction with sulfuric acid solution. The cross-linked membranes were characterized by Fourier transform infrared (FTIR), X-ray diffraction (XRD), Scanning Electron Microscopy (SEM), X-ray Dispersive Energy Spectroscopy (EDX) and contact angle measurements. The biological assays of the membranes were performed with NIH 3T3 cells in two steps: evaluation of cytotoxicity by indirect contact of the cells with the extracts of the chitosan membranes and finally with the direct contact of the cells on the filaments of chitosan to obtain adhesion and cell proliferation information. Non-crosslinked membranes of chitosan were used as controls for all assays. With the physicochemical tests, it was possible to observe an effective crosslinking reaction in chitosan. Biological assays have revealed that the membranes are non-cytotoxic but must still be modified to provide cell adhesion and proliferation.
\end{abstract}

\section{Subject Areas}

Biochemistry, Bioengineering, Biological Materials, Cell Biology 


\section{Keywords}

Chitosan, Crosslinking, Biomedical Application

\section{Introduction}

Chitosan is a polymer with unique and valuable characteristics, being a material with relevant technological and economic characteristics, possessing biological properties as biocompatibility, bioactivity and biodegradability, besides being non-toxic and produced by natural sources renewable. Chitosan biodegradability is due to the polymers metabolism by some human enzymes, such as lysozyme. This property is consistent with one of the primary requirements of a biodegradation process, which is to be susceptible to an enzymatic hydrolysis reaction. Besides, chitosan could be produced in various forms, such as films, membranes and porous structures, and allows applications in the most diverse areas. It stands out as an advantage of working and obtaining chitosan membranes-in their high permeability in water, ability to immobilize microorganisms, besides accelerating the healing process of wounds, especially when compared with other materials, such as membranes of polyurethane [1]-[6].

Biomedical applications of chitosan have generated opportunities for production of specialized biomaterials, mainly with chemical and physical modifications, which have promoted new biological activities for specific purposes. Chitosan and its modifications find applications in several biomedical fields, including Tissue Engineering and Controlled Drug Delivery Systems. Although chitosan has an excellent number of properties, some of them especially desired for a specific application may be constituted by a chitosan modification. The presence of functional groups such as $-\mathrm{NH}_{2}$ and $-\mathrm{OH}$ in the chitosan molecule allows interactions with other polymers and molecules, and one way of chemically modifying chitosan is through crosslinks, which are often used to improve or even confer properties to the polymeric materials [7] [8] [9].

Although chitosan processing technology is well known and often used by research groups, there are still some inconveniences that could be avoided in order to facilitate the production of chitosan-based materials. Currently, the most commonly used crosslinking agents are dialdehydes, such as glyoxal, and particularly, glutaraldehyde [10] [11]. However, the main disadvantage of these reagents is that they are considered toxic, especially if they are found in free traces, leading to the risk of formation of toxic products by reaction between the substrate and the crosslinking agent during the biodegradation process in vivo. Glutaraldehyde is known to be neurotoxic and glyoxal is mutagenic. One method of overcoming this disadvantage is the preparation of ion-crosslinked materials. Ionic crosslinks are simple and fast processes, which makes them of great interest for medical and pharmaceutical applications. Genipine and tripolyphosphate (TPP) have been applied in this sense with a great deal of emphasis 
[3] [8] [12] [13] [14] [15] [16]. Studies have shown the use of sulfuric acid as a crosslinking agent to be applied as materials for proton exchange and evaporation, as studied by Devi et al. [17] and Cui et al. [18]. However, its application in the biomedical field, until the present moment, has not been studied yet for biomedical applications.

Hence, the aim of this work was to produce ionically crosslinked chitosan membranes through ionic crosslinking with a solution of sulfuric acid in several reaction times for biomedical application.

\section{Materials and Methods}

\subsection{Materials}

Chitosan (medium molecular weight and deacetylation degree $\approx 75 \%-85 \%$ ), Phosphate Buffer Solution (PBS) were purchased from Sigma Aldrich, acetic acid $\left(\mathrm{CH}_{3} \mathrm{COOH}\right)$ was purchased from Vetec and used as received. All reagents were of analytical grade and used without further purification.

For the cytotoxicity and cell adhesion assays, the NIH 3T3 cell line, with passage 162 (10,000 cells/well) and 169 (40,000 cells well) were respectively used, were cultured with DMEM (Dulbecco's Modified Eagle's Medium, GIBCO) with glucose and GLUTAMAX-1, containing 10\% fetal bovine serum (GIBCO) and $1 \%$ antibiotic/antimycotic (GIBCO). To perform the subculture of the cells, a $0.25 \%$ trypsin solution was added to the cell culture dish. Cells cultured directly on the surface of the cell culture dish were used as reference.

The HFF 1 cell line, with passage 6, was cultured with DMEM (Dulbecco's Modified Eagle's Medium, GIBCO) with glucose and GLUTAMAX-1, containing $15 \%$ fetal bovine serum (GIBCO) and $1 \%$ anti-biotic/antimycotic (GIBCO), with a cell density of 25,000 cells/well. To perform subculture of the cells, a trypsin solution $(0.25 \%)$ was added to the cell culture dish. Cells cultured directly on the surface of the cell culture dish were used as reference.

Chitosan membranes preparation

Chitosan membranes were prepared following previous work by Karakeşili [13] and Dallan [19]. Briefly, chitosan solutions were prepared by dissolving chitosan powder in a $1 \%(\mathrm{v} / \mathrm{v})$ acetic acid solution to form a final solution with a $2.0 \mathrm{wt} \%$ concentration. Afterwards, the solutions were filtered to remove insoluble residues. After complete dissolution and filtration, the prepared solutions were poured into $11 \mathrm{~cm}$ diameter Petri dishes, with a final volume in each $30 \mathrm{ml}$ dish of solution. The plates were oven-dried at a constant temperature of $50^{\circ} \mathrm{C}$ for a period of 24 hours for complete evaporation of the solvent. A Sodium hydroxide solution $(1 \mathrm{~mol} / \mathrm{L})$ was added onto membranes, for 2 hours, to complete removal of acidic wastes. After the alkaline reaction, the membranes were immersed in distilled water. After a period of 48 hours immersed in distilled water, the membranes were subjected to stretching and drying in circular ceramic molds, at a controlled temperature of $25^{\circ} \mathrm{C}$, for 24 hours.

Crosslinking reaction 
For the introduction of the crosslinks, an adapted methodology was developed by Karakeşili [13] and Cui [18]. The membranes were immersed in sulfuric acid solution $(0.01 \mathrm{~mol} / \mathrm{L})$, obtaining five different samples with the following reaction times: 5, 15, 30, 60 and 90 minutes. After the exposure times, the samples were washed with distilled water until neutral $\mathrm{pH}$ was reached.

\subsection{Characterizations}

\subsubsection{Characterization}

The characterization of the crosslinked chitosan membranes was splitted into two steps: the first one with the physico-chemical characterization to evaluate the interaction between polymer and crosslinking agent and the second one with biological characterization to evaluate the cytotoxic potential of the membranes and possible influence of the crosslinking agent on this result.

\subsubsection{FTIR}

Chitosan samples were characterized by FTIR using an AVATAR TM 360 ESP Nicolet spectrometer (DEMa/CCT/UFCG) and with a scan of 4000 to $400 \mathrm{~cm}^{-1}$, without the need for preparation of $\mathrm{KBr}$, since all the samples were in the form of membranes.

\subsubsection{XRD}

The samples were submitted to X-ray diffraction analysis (XRD 6000) (DEMa/ CCT/UFCG) with angular scanning of $5^{\circ}<2 \theta<35^{\circ}$, in the Bragg-Brentano $2 \theta$, using $\mathrm{Cu}(\mathrm{ka1})$ radiation with $0.02(2 \theta)$ scanning, with a 0.5 second interval for each sample.

\subsubsection{SEM}

The crosslinked and non-crosslinked chitosan membranes were morphologically characterized by scanning electron microscopy using an electron microscope model TM 1000 HITACHI (CERTBIO/UFCG). There was no need for further coating with gold particles, since it is low-voltage equipment.

\subsubsection{Contact Angle}

The surface energy and the hydrophilic/hydrophobic character were evaluated by measuring the surface tension in equipment developed and installed in the CERTBIO/UFCG. The contact angle analyzes were performed with the distilled water drip on the surface of the film, with subsequent analysis of the measurements of the angles formed by the water bubble in the film, with software of the CERTBIO/UFCG.

\subsubsection{Cytotoxicity}

To prepare extracts, the membranes were immersed in sterile PBS ( $500 \mu \mathrm{L} / \mathrm{Well})$ in cell culture dishes ( $\mathrm{n}=3$ for each sample), incubated for seven days at $37^{\circ} \mathrm{C} / 5 \% \mathrm{CO}_{2}$, without shaking. After the incubation period, the extracts were collected from the plates and poured into eppendorfs. Several dilutions (1:100, $1: 20,1: 10,1: 5,1: 2)$ were performed with the extracts of the membranes, pure 
and cross-linked.

The cytotoxicity of the chitosan membranes was evaluated by determining the percentage of cell viability using the resazurin reduction method, which establishes a correlation between the cellular metabolic activity and the number of viable cells in culture. NIH 3T3 cells were seeded in 96-well plates with a cell density of 10,000 cells/well. After 24 hours, the medium was removed and $80 \mu \mathrm{L}$ of DMEM were added. $20 \mu \mathrm{L}$ of the extracts, with all dilutions, with five replicates for each sample, were added to the wells. Every two days, the preparation (medium + extract) was changed, until a final period of seven days for evaluation. At the end of the seven days, the old medium was changed to a new medium, this time containing $10 \%$ rezasurin, followed by incubation for 3 hours at $37^{\circ} \mathrm{C} / 5 \% \mathrm{CO}_{2}$. After the 3 hour period, $100 \mu \mathrm{L}$ of the medium was removed and the fluorescence of the resorufin was measured in a Victor3 1420 model reader, PerkinElmer at $540 \mathrm{~nm}$ with a reference filter of $620 \mathrm{~nm}$. Cell viability was calculated using the equation:

$$
\text { Viab\% }=\frac{100 \times \text { OD570e }}{\text { OD570b }}
$$

where OD570e is the mean value of the measured optical density of the test sample, and OD570b is the mean value of the measured optical density of the blanks.

\subsubsection{Cell Adhesion}

For the cell adhesion assays, NIH $3 \mathrm{~T} 3$ cells were grown directly on the membranes in a 24 -well plate with a cell density of 40,000 cells/well, in the following times: $1 \mathrm{~h}, 4 \mathrm{~h}, 12 \mathrm{~h}, 24 \mathrm{~h}$, and $48 \mathrm{~h}$. Cell adhesion was evaluated by determining the percentage of cell viability using the rezasurin reduction method, which establishes a correlation between cell metabolic activity and the number of viable cells in culture [19] (PERROT et al., 2003). Following contact time, the medium was removed, followed by washing with sterile PBS, to remove unbound cells from the polymer surface, and $550 \mu \mathrm{L}$ of DMEM + resazurin was added to each well, followed by incubation for 3 hours at $37^{\circ} \mathrm{C} / 5 \% \mathrm{CO}_{2}$. After the 3 hour period, $100 \mu \mathrm{L}$ of the medium was removed and the fluorescence of resorufin was measured in a Victor3 1420 reader, PerkinElmer.

\subsubsection{Statistical Analyzes}

Statistical analyzes were performed using the GraphPad prism 5.0 program, using ANOVA $(p<0.05)$ with Boferroni Post Hoc test.

\section{Results and Discussion}

\subsection{FTIR}

The infrared spectra obtained from the non-crosslinked and crosslinked chitosan membranes are shown in Figure 1(a) and Figure 1(b).

According to the spectrum formed, it can be seen in Figure 1 that the supplied chitosan is not $100 \%$ deacetylated, confirmed by the band found in the 


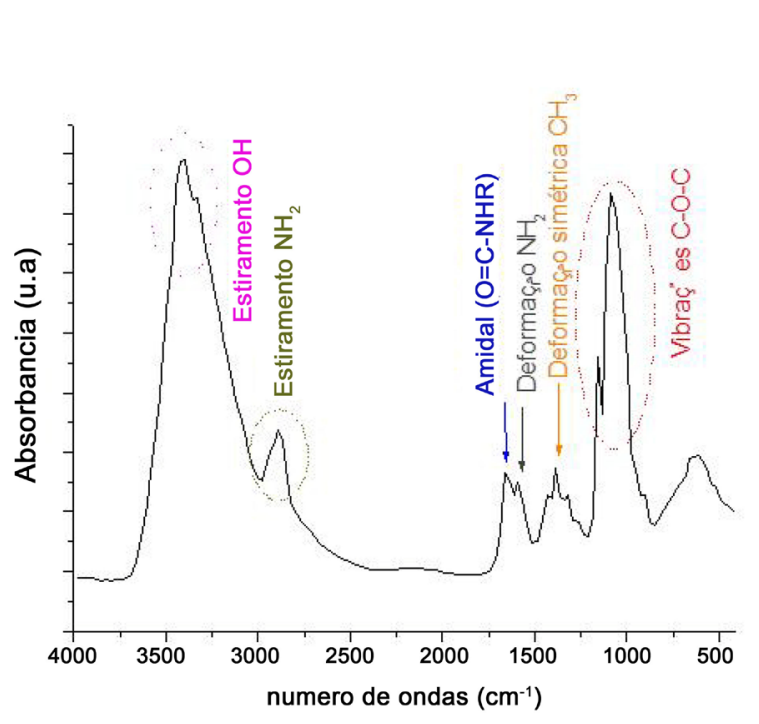

(a)

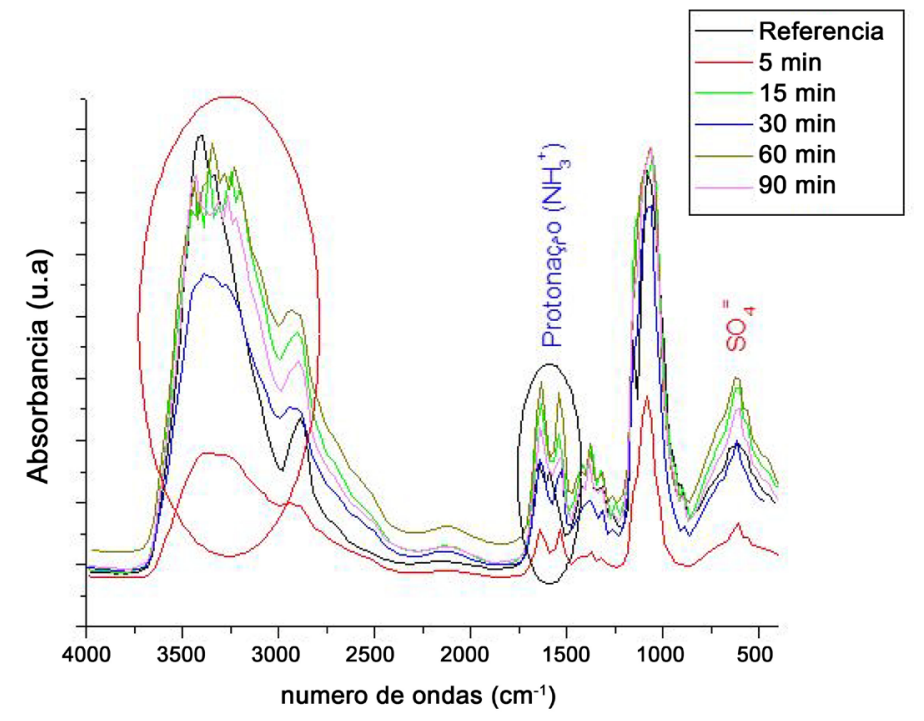

(b)

Figure 1. (a) FTIR of pure chitosan film and (b) FTIR of crosslinked chitosan membranes.

$1658 \mathrm{~cm}^{-1}$ region, characteristic of an amide $\mathrm{I}(\mathrm{O}=\mathrm{C}-\mathrm{NHR})$. It still exhibits a strong and wide band in the region of $3409 \mathrm{~cm}^{-1}$ with the appearance of a shoulder at $3340 \mathrm{~cm}^{-1}$, which are attributed to an overlap in the stretches of the functional groups $\mathrm{OH}$ and $\mathrm{NH}_{2}$, due to the hydrogen bonds formed in the polymer chain [13] [20] [21].

As the time of crosslinking reaction increases in the samples (Figure 1(b)), changes can be observed, characterizing the crosslinking process in specific bands: in the $1592 \mathrm{~cm}^{-1}$ region related to $\mathrm{NH}_{2}$ deformation, the band intensity begins to weaken, due to the protonation with the $\mathrm{H}^{+}$ions released by the acid dissociation. Similar behavior was observed in the bands found between 3000 and $3500 \mathrm{~cm}^{-1}$, with a clear widening at the base of the band located in the region of approximately $2900 \mathrm{~cm}^{-1}$. With this enlargement, it is possible to admit a decrease in the intensity of the hydrogen bonds, thus evidencing the formation of crosslinks, since the hydrogen bonds contribute to the formation of the crystalline structure of the chitosan. Finally, the presence of sulfate groups was ratified by absorption in the region of $614 \mathrm{~cm}^{-1}$, thus confirming the effective crosslinking reaction of chitosan membranes.

\subsection{XRD}

The XRD results obtained from the non-crosslinked and crosslinked chitosan membranes are shown in Figure 2.

According to the diffractogram obtained from the pure chitosan film, a typical behavior of semicrystalline polymers, with broad base peaks found at $2 \theta=10^{\circ}$ and $2 \theta=20^{\circ}$, could be observed. Chitosan has a semi-crystalline profile due to strong intra- and intermolecular interactions, characterized by the hydrogen bonds formed between the amine, alcohol, amide groups and other functional groups present in the chitosan molecule. These strong interactions provide some 


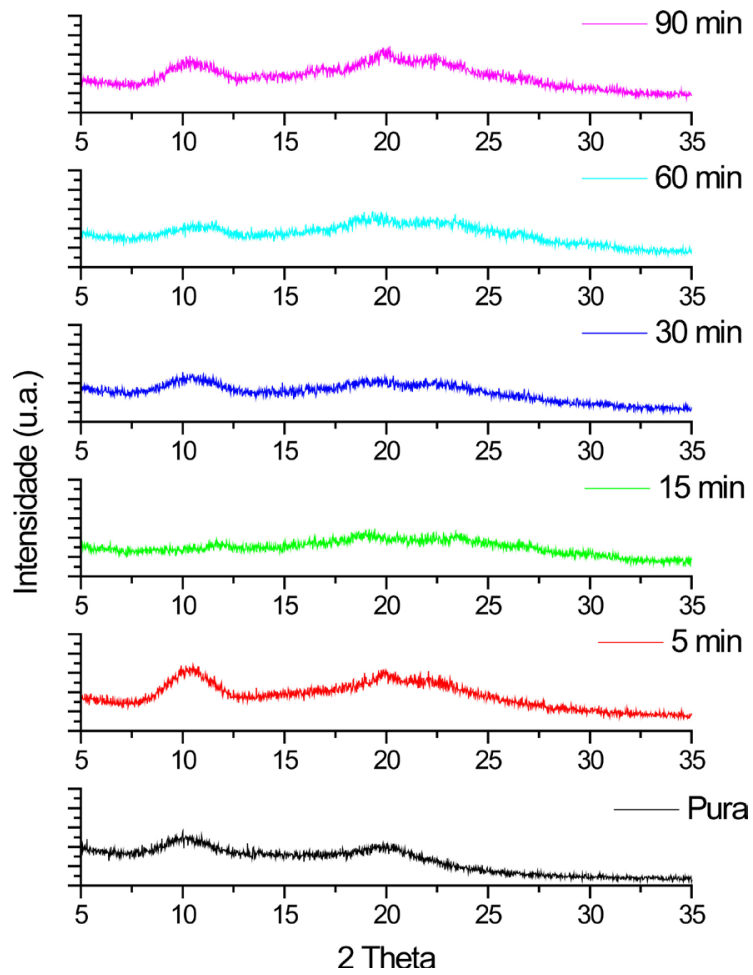

Figure 2. XRD of pure and crosslinked chitosan membranes.

organization to the crystalline structure of chitosan [21] [22].

As observed in the infrared spectra, the XRD results of the crosslinked samples demonstrate the effective crosslinking reaction between the chitosan and sulfuric acid membranes, due to the decrease in the intensity of the peaks in relation to those of the non-crosslinked film. In addition, observed the results, it was observed for the 15 and 30 minutes times, there was a greater decrease in the semi-crystalline profile of the membranes. However, in crosslinked membranes at 60 and 90 minutes, a discrete increase in crystallinity occurred, leading to a spectrum similar to the pure condition. Such behavior was not observed for the other crosslinking conditions. These results were evidenced in the analysis by X-ray Dispersive Energy spectroscopy. As the ionic crosslinks are characterized by producing reversible bonds in the system, and with the increase of time of exposure of the chitosan membranes to the sulfuric acid solution, there was a saturation of $\mathrm{H}^{+}$ions, produced by the dissociation of the acid. This saturation caused a shift towards the chemical equilibrium of the reaction, with $\mathrm{H}^{+}$ions capturing $\mathrm{SO}_{4}^{2-}$ ions.

This decrease in the intensity of the crystalline peaks of chitosan is justified by the incorporation of the sulfate ions between the polymer chains. Thus, the sulfate ion blocks the formation of hydrogen bonds, thereby tracing a profile of crosslinked polymers, that is, polymers with low or no crystallinity.

\subsection{SEM}

The micrographs obtained from the non-crosslinked and crosslinked chitosan 

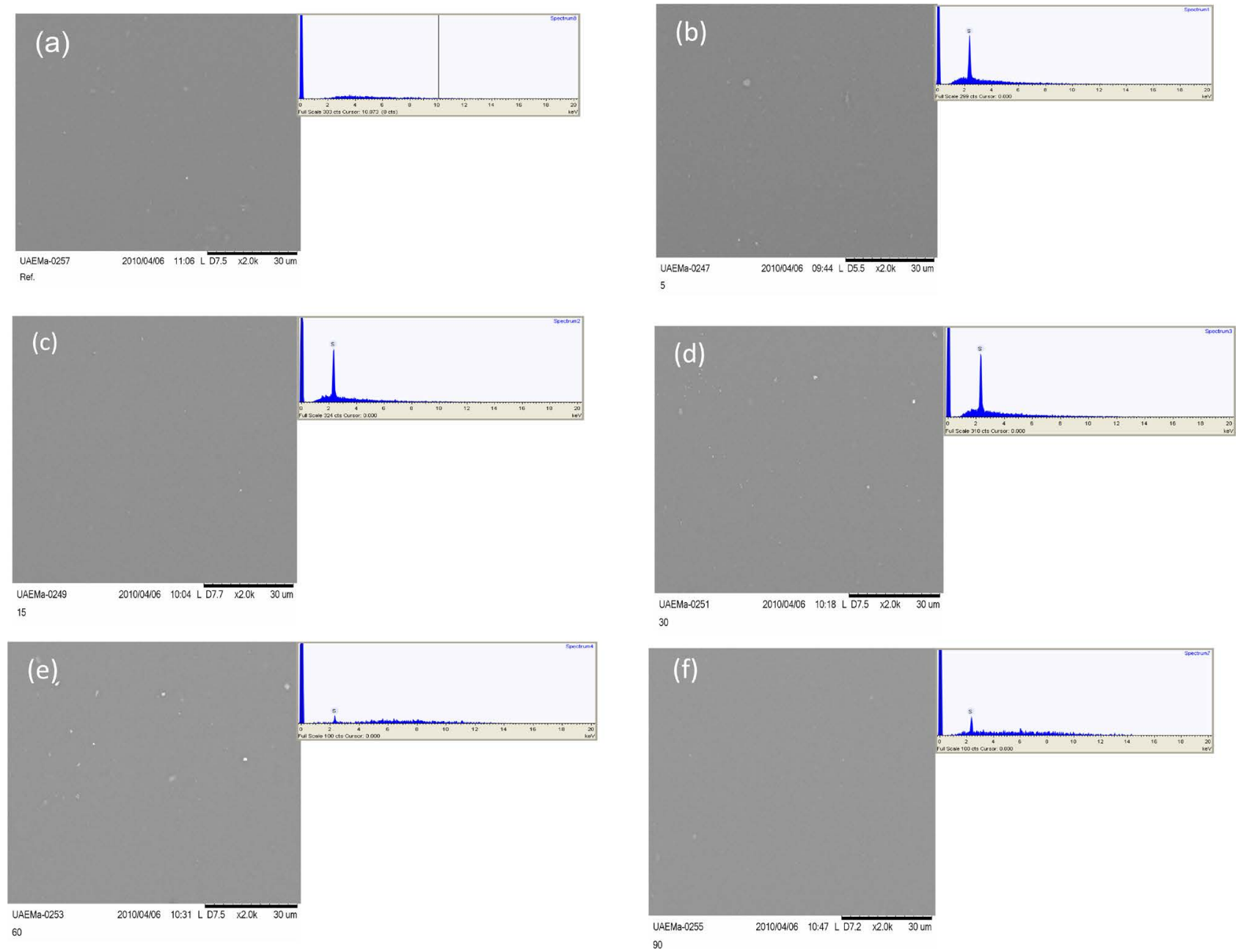

Figure 3. MEV and EDX of the pure membranes (a) and crosslinked (b) $5 \mathrm{~min}$, (c) $15 \mathrm{~min}$, (d) $30 \mathrm{~min}$, (e) $60 \mathrm{~min}$, (f) $90 \mathrm{~min}$. $2000 \mathrm{X}$.

membranes, as well as the respective EDX results are shown in Figure 3.

The morphology of the pure chitosan film (without the introduction of crosslinks), a smooth flat surface was observed, without the presence of pores, characterizing the membranes as dense. Marreco [23] and Dallan [19] also studied the morphology of dense chitosan membranes, also finding a flat and dense surface. Even after the crosslinking reactions, no significant differences were shown in the microstructure of the membranes, with the surface remaining flat and without the presence of pores and/or defects.

The presence of sulfur in the membranes was observed at 5, 15, 30, 60 and 90 minutes times the results of X-ray diffractive spectroscopy analysis. However, for the 60- and 90-minute reaction times, low sulfur ions were found in relation to the other reaction times, which may be indicative of a decrease in crosslinking as already discussed in infrared and X-ray diffraction. As the ionic crosslinks are characterized by producing reversible bonds in the system, and with the increase of time of exposure of the chitosan membranes to the sulfuric acid solution, there was a saturation of $\mathrm{H}^{+}$ions, produced by the dissociation of the acid. This 
saturation caused a shift towards the chemical equilibrium of the reaction, with $\mathrm{H}+$ ions capturing $\mathrm{SO}_{4}^{2-}$ ions.

\subsection{Contact Angle}

The contact angle measurements of the non-crosslinked and crosslinked chitosan membranes are shown in Figure 4.

With the contact angle analysis (Figure 4), it was observed that the non-crosslinked film of chitosan presented a measure of contact angle above $50^{\circ}$. Furthermore, it was observed that with the introduction of the crosslinks in the chitosan membranes, there was a decrease in the contact angle values.

A low contact angle indicates a higher hydrophilic profile, and these results indicate that the sulfuric acid, as a crosslinking agent, increased the hydrophilic profile of the crosslinked membranes, with all values below the pure film measurement used as control. Analyzing the results, the lowest contact angles were found for the samples with 15 and 30 minutes of reaction, indicating a higher crosslinking reaction in these membranes. As previously discussed, the reversible character of the ionic crosslinks, with the contact angle measurements, shows a slight tendency of the increase of the wetting angle for the cross-linked membranes with 60 and 90 minutes. With this, it can be said that there was a tendency of the system to return to its initial state.

\subsection{Cytotoxicity}

The results of the cytotoxicity test for the various dilutions of the extracts prepared from the crosslinked and non-crosslinked chitosan membranes are shown in Figure 5. The samples were named A, B, C, D, E and F for the six situations (pure, 5, 15, 30, 60 and 90 minutes, respectively).

Cell viability was assessed using the resazurin reduction method. When observing the graph, the cellular metabolic activity for all the dilutions presented values above $80 \%$, and that statistically $(p<0.05)$, there were no significant differences. Therefore, it can be considered that no sample had a cytotoxic character in contact with NIH 3T3 cells. This makes it possible to state that none of the chitosan membranes releases products that are toxic in contact with the cells.

The results of cell viability for the exposure times of 60 and 90 minutes, in all

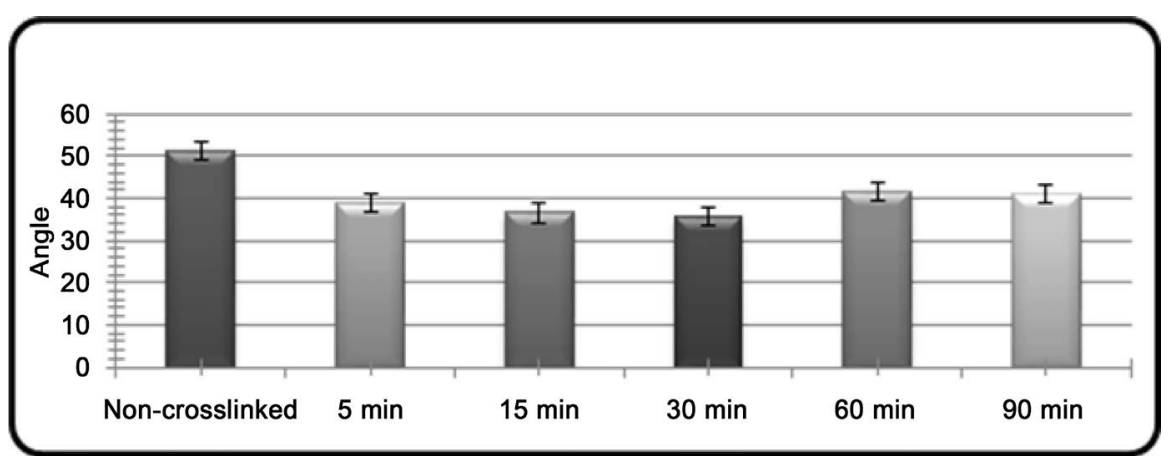

Figure 4. Contact angles of non-crosslinked and crosslinked chitosan membranes. 
dilutions, also show that there was a tendency of the values to be equal to those of the pure chitosan film, showing that in fact, there are a reversibility in the system.

\subsection{Cell Adhesion}

The NIH $3 \mathrm{~T} 3$ cell line was used to evaluate cell adhesion in the chitosan membranes, crosslinked and non-crosslinked. The results of the cell adhesion assays with the NIH 3T3 cell line are shown in Figure 6.

The cell adhesion in the chitosan membranes, pure and crosslinked, were evaluated through direct contact between the surface of the membranes and the cell suspension, with contact times established at 1, 4, 24 and 48 hours, with the

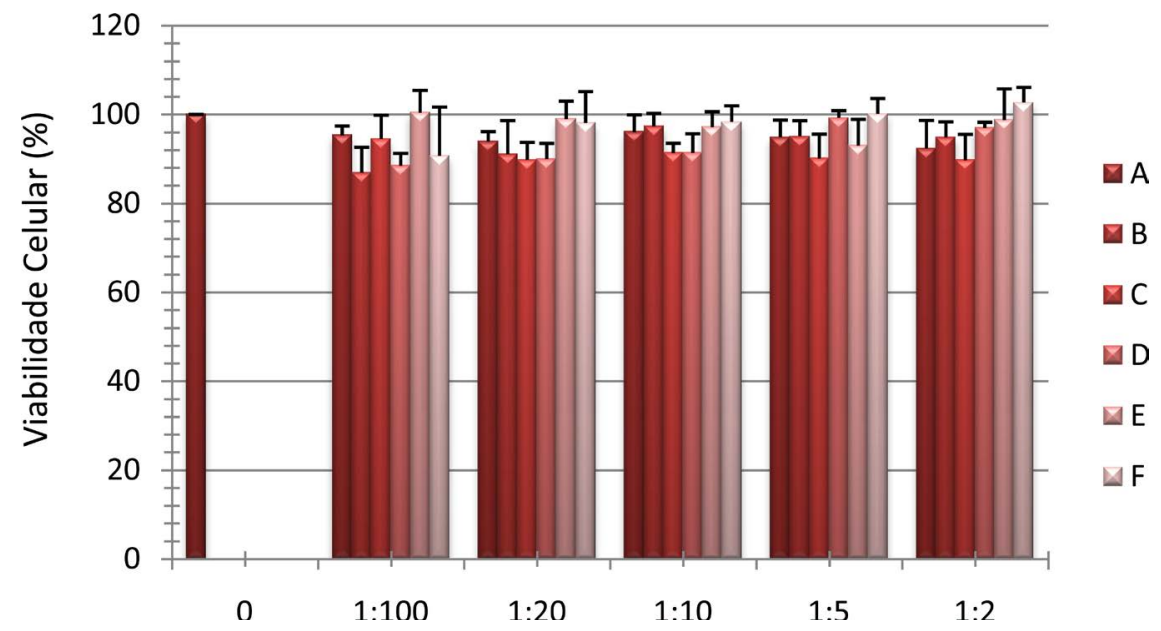

Figure 5. Cell metabolic activity in contact with extracts of chitosan membranes.

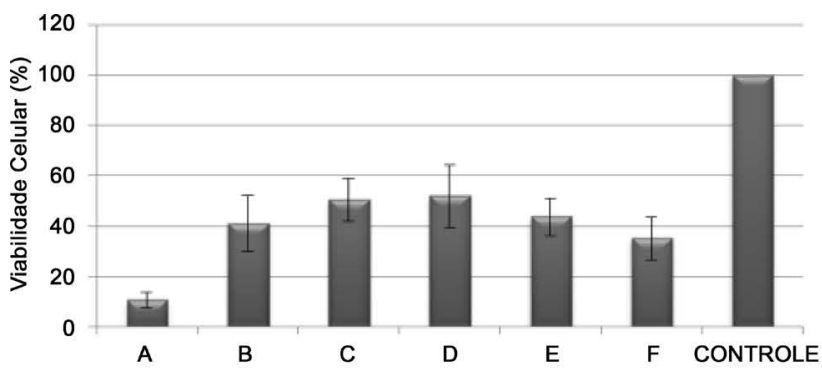

(a)

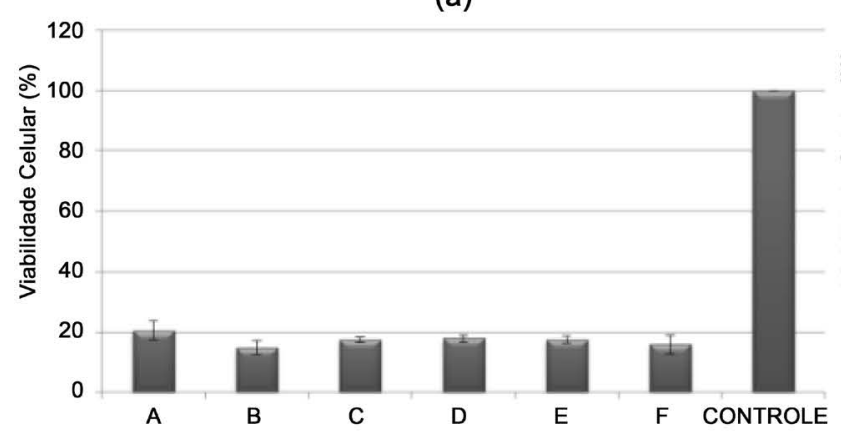

(c)

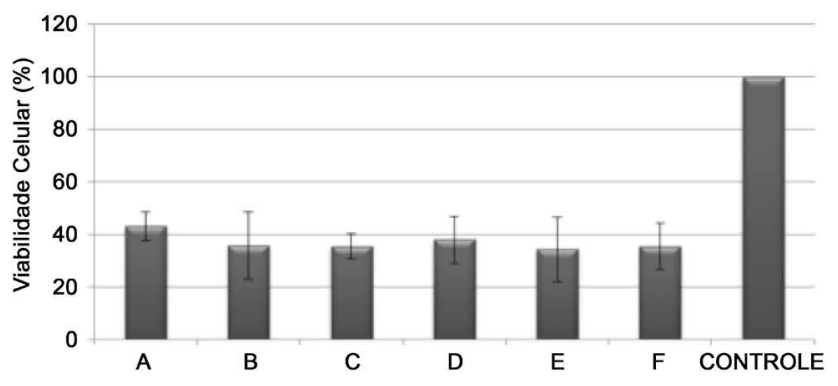

(b)

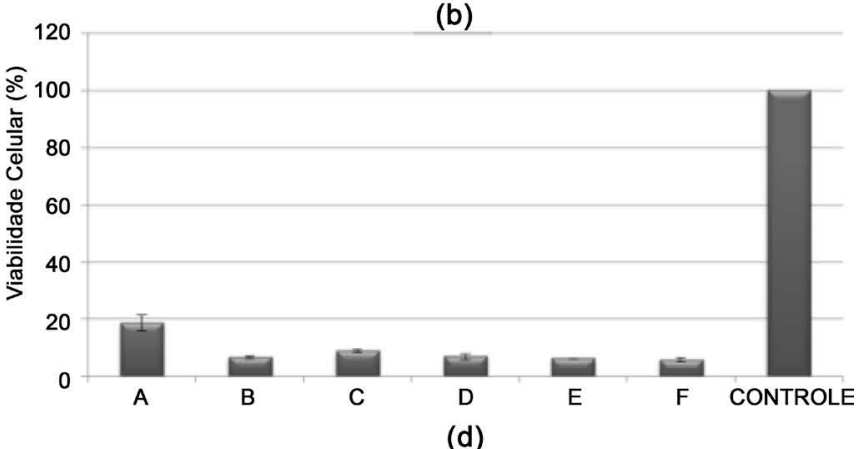

(d)

Figure 6. Results of the cell adhesion assays: (a) 1 hour, (b) 4 hours, (c) 24 hours and (d) 48 hours. 
cell culture plate being used as positive control. Cell adhesion was assessed by cell viability measurement using the resazurin reduction method.

The results presented values well below the values presented by the positive control, with values statistically lower than those presented by the control $(p<$ 0.05), for all the trials.

For the 1-hour contact time, the ionically crosslinked membranes presented higher values of cell visibility than that presented by the pure chitosan film, with significant statistical differences. As for the exposure time of 4 hours and 24 hours, no significant statistical difference $(p<0.05)$ was observed between the crosslinked membranes and the pure film. However, for 48 hours, all viability values were below that found with pure film.

According to Farkhry [24] some factors may inhibit the adhesion and proliferation of fibroblasts on chitosan surfaces, for example, manipulation may interfere with this process as well as the intrinsic properties of chitosan, such as molecular weight and degree deacetylation. Furthermore, cell adhesion property is affected by several factors, including surface characteristics such as surface chemistry, charge density, roughness and morphology [14] [25] [26].

\section{Conclusions}

The method of crosslinking applied in this study allowed an improvement in the preparation of chitosan membranes. The results were promising, providing good stability conditions as well as another important factor was even employing an acid as a crosslinking agent, with the cytotoxicity tests it was proved that the crosslinked membranes did not produce cytotoxic effects on the cells. However, cell adhesion assays have shown that the film does not provide cell adhesion and proliferation, with all values below the control. Thus, these novel produced membranes could be used in various biomedical applications, such as grafts, a carrier for controlled drug release system and wound healing bandages for tissue engineering.

The research described in this work described several aspects regarding the production of chitosan membranes, highlighting three main points: properties of the produced material, morphological characteristics and cytotoxic effects. In general, the present work offered a new methodology for the manufacture of chitosan membranes, producing satisfactory materials with a simple strategy based on the application of an adhesive material to obtain chitosan membranes.

\section{Acknowledgements}

The financial support from Coordenação de Aperfeiçoamento de Pessoal de Nível Superior/CAPES and Brazilian Ministry of Health and Centro de Química da Madeira and Molecular Materials Research Group (Projeto PEst-OE/QUI/ UI0674/2011-FCT) are gratefully acknowledged.

\section{Conflict of Interest}

The authors declared no conflict of interest. 


\section{References}

[1] Campana, S.P. and Signini, R. (2001) Efeitos de Aditivos na Desacetilação de Quitina. Polímeros: Ciência e Tecnologia, 11, 169-173. https://doi.org/10.1590/S0104-14282001000400006

[2] Triplett, R.G., Schow, S.R. and Fields, R.T. (2001) Bone Augmentation with and without Biodegradable and Nonbiodegradable Microporous Membranes. Oral \& Maxillofacial Surgery Clinics of North America, 13, 411-422.

[3] Berger, J., Reist, M., Mayer, J.M., Felt, O., Peppas, N.A. and Gurny, R. (2004) Structure and Interactions in Covalently and Ionically Crosslinked Chitosan Hydrogels for Biomedical Applications. European Journal of Pharmaceutics and Biopharmaceutics, 57, 19-37. https://doi.org/10.1016/S0939-6411(03)00161-9

[4] Senel, S. and Mcclure, S.J. (2004) Potential Application of Chitosan in Veterinary Medicine. Advanced Drug Delivery Reviews, 56, 1467-1480.

https://doi.org/10.1016/j.addr.2004.02.007

[5] Bettini, R., Romani, A.A., Morganti, M.M. and Borghetti, A.F. (2008) Physicochemical and Cell Adhesion Properties of Chitosan Films Prepared from Sugar and Phosphate-Containing Solutions. European Journal of Pharmaceutics and Biopharmaceutics, 68, 74-81. https://doi.org/10.1016/j.ejpb.2007.03.026

[6] Croisier, F. and Jérôme, C. (2013) Chitosan-Based Biomaterials for Tissue Engineering. European Polymer Journal, 49, 780-792.

https://doi.org/10.1016/j.eurpolymj.2012.12.009

[7] Subramanian, A., Rau, A.V. and Kaligotla, H. (2006) Surface Modification of Chitosan for Selective Surface Protein Interaction. Carbohydrate Polymers, 66, 321-332. https://doi.org/10.1016/j.carbpol.2006.03.022

[8] Laranjeira, M.C.M. and Fávere, T. (2009) Quitosana: biopolímero funcional com potencial industrial biomédico. Química Nova, 32, 672-678.

https://doi.org/10.1590/S0100-40422009000300011

[9] Shukla, S.K., Mishra, A.K., Arotiba, O. and Mamba, B.B. (2013) Chitosan-Based Nanomaterials: A State-Of-Art Review. International Journal of Biological Macromolecules, 59, 46-58. https://doi.org/10.1016/j.ijbiomac.2013.04.043

[10] Neto, C.G.T., Giacometti, J.A., Job, A.E., Ferreira, F.C., Fonseca, J.L.C. and Pereira, M.R. (2005) Thermal Analysis of Chitosan Based Networks. Carbohydrate Polymers, 62, 97-103. https://doi.org/10.1016/j.carbpol.2005.02.022

[11] Yang, B., Li, X., Kong, X., Guo, G., Huang, M., Luo, F., Wei, Y., Zhao, X. and Qian, Z. (2010) Preparation and Characterization of a Novel Chitosan Scaffold. Carbohydrate Polymers, 80, 860-865. https://doi.org/10.1016/j.carbpol.2009.12.044

[12] Beppu, M.M., Vieira, R.S., Aimali, C.G. and Santana, C.C. (2007) Crosslinking of Chitosan Membranes Using Glutaraldehyde: Effect on Ion Permeability and Water Absorption. Journal of Membrane Science, 301, 126-130. https://doi.org/10.1016/j.memsci.2007.06.015

[13] Karakeçili, A.G., Satriano, C., Gümüsderelioglu, M. and Marletta, G. (2007) Surface Characteristics of Ionically Crosslinked Chitosan Membranes. Journal of Applied Polymer Science, 106, 3884-3888. https://doi.org/10.1002/app.26920

[14] Chiono, V., Pulieri, E., Vozzi, G., Ciardelli, G., Ahluwalia, A. and Giusti, P. (2008) Genipin-Crosslinked Chitosan/Gelatin Blends for Biomedical Applications. Journal of Material Science: Materials in Medicine, 19, 889-898. https://doi.org/10.1007/s10856-007-3212-5

[15] Muzzarelli, R.A.A. (2009) Chitin and Chitosan for the Repair of Wounded Skin, 
Nerve, Cartilage and Bone. Carbohydrate Polymers, 76, 167-182. https://doi.org/10.1016/j.carbpol.2008.11.002

[16] Pujana, M.A., Pérez-Álvarez, L., Iturbe, L.C.C. and Katime, I. (2013) Biodegradable Chitosan Nanogel Crosslinked with Genipin. Carbohydrate Polymers, 94, 836-842. https://doi.org/10.1016/j.carbpol.2013.01.082

[17] Devi, D.A., Smitha, B., Sridhar, S. and Aminabhavi, T.M. (2005) Pervaporation Separation of Isopropanol/Water Mixtures through Crosslinked Chitosan Membranes. Journal of Membrane Science, 262, 91-99. https://doi.org/10.1016/j.memsci.2005.03.051

[18] Cui, Z., Xiang, Y., Si, J., Yang, M., Zhanf, Q. and Zhang, T. (2008) Ionic Interactions between Sulfuric Acid and Chitosan Membranes. Carbohydrate Polymers, 73, 111-116. https://doi.org/10.1016/j.carbpol.2007.11.009

[19] Dallan, R.M. (2005) Síntese e caracterização de membranas de quitosana para aplicação na regeneração da Pele. Tese, Doutorado em Engenharia Química, Universidade Estadual de Campinas, Faculdade de Engenharia Química, Campinas, $194 \mathrm{p}$.

[20] Tsai, H.S. and Wang, Y.Z. (2008) Properties of Hydrophilic Chitosan Network Membranes by Introducing Binary Crosslink Agents. Polymer Bulletin, 60, 103-113. https://doi.org/10.1007/s00289-007-0846-x

[21] Ostrowska-Czubenko, J. and Gierszewska-Drużyńska, M. (2009) Effect of Ionic Crosslinking on the Water State in Hydrogel Chitosan Membranes. Carbohydrate Polymers, 77, 590-598. https://doi.org/10.1016/j.carbpol.2009.01.036

[22] Uragami, T. and Tokura, S. (2006) Materials Science of Chitin and Chitosan. Kodansha Ltd., Japan.

[23] Marreco, R., Moreira, L., Genari, S.C. and Moraes, A.M. (2004) Effect of Different Sterilization Methods on the Morphology. Mechanical Properties, and Cytotoxicity of Chitosan Membranes Used as Wound Dressings. Journal of Biomedical Materials Research Part B: Applied Biomaterials, 71A, 268-277. https://doi.org/10.1002/jbm.b.30081

[24] Farkhry, A., Schneider, G.B., Zaharias, R. and Senel, S. (2004) Chitosan Supports the Initial Attachment and Spreading of Osteoblasts Preferentially over Fibroblasts. Biomaterials, 25, 2075-2079. https://doi.org/10.1016/j.biomaterials.2003.08.068

[25] Tremei, A., Cai, A., Tirtaatmadja, N., Hughes, B.D., Stevens, G.W., Landman, K.A. and O’Connor, A.J. (2009) Cell Migration and Proliferation during Monolayer Formation and Wound Healing. Chemical Engineering Science, 64, 247-253. https://doi.org/10.1016/j.ces.2008.10.008

[26] Hamilton, V., Yuan, Y., Rigney, D.A., Puckett, A.D., Ong, J.L., Yang, Y., Elder, S.H. and Bumgardner, J.D. (2006) Characterization of Chitosan Films and Effect on Fibroblast Cell Attachment and Proliferation. Journal of Material Science: Materials in Medicine, 17, 1373-1381. https://doi.org/10.1007/s10856-006-0613-9 